\title{
Design hazard identification and the link to site experience
}

Graham Hayne MSc, CEng, MICE, PhD

Researcher, School of Engineering and the Built Environment, Glasgow Caledonian University, Glasgow, UK (corresponding author: ghayne10@caledonian.ac.uk)

\author{
Bimal Kumar BEng (Hons), MSc, PhD, MBCS, MASCE \\ Professor, School of Engineering and the Built Environment, Glasgow \\ Caledonian University, Glasgow, UK \\ Billy Hare PhD, BSC (Hon), BA, MCIOB \\ Professor, School of Engineering and the Built Environment, Glasgow \\ Caledonian University, Glasgow, UK
}

The training, development and routes to charteredship of building design engineers have undergone a major transformation in recent years. Additionally, the duration and quality of site experience being gained by designers is reducing. While accident causation is often complex, previous research shows a potential link between design and construction accidents. The effectiveness of the UK's Construction (Design and Management) (CDM) Regulations is being questioned, and designers regularly do not recognise the impact they can make on site safety. A newly developed hazard perception test was used to determine if students and design practitioners are able to identify hazards in designs and to establish if site experience impacts hazard identification. The results of the tests show an association between the ability to identify and mitigate hazards and possession of site experience. The results provide empirical evidence that supports previous anecdotal evidence. The results also question if the design engineers of today are suitably equipped to fulfil the designer's responsibilities under the CDM Regulations.

\section{Introduction}

In recent years the education and training of UK engineers aiming for chartered status with the Institution of Civil Engineers (ICE) and Institution of Structural Engineers (IStructE) has undergone significant changes. Formerly, entrants to the profession either gained a bachelor's degree from a university (or, pre-1992, a polytechnic degree) or progressed through an academic route of day release and evening classes while working. This arrangement provided design offices with staff of varied and complementary experiences, both academic and practical. With few exceptions, a master's degree is now required to become chartered, which may limit the diverse experiences within offices. At the same time, extended periods of site experience are no longer required to achieve chartered status (ICE, 2015; IStructE, 2014) provided that applicants can demonstrate compliance of the training objectives, such as '[a] sound knowledge of legislation, hazards and safe systems of work' (ICE, 2015: p. 12). A similar situation occurs in other countries where periods of site experience are not required as part of the training programme (ASCE, 2016).

Construction is known to be a hazardous environment with many accidents having a necessary (not sufficient) link to the design outputs upstream of the construction process. Many in the industry believe that designers have a moral and ethical obligation to reduce hazards in design (Crossrail, 2016) while, in the UK, the Construction Design and Management Regulations (HMG, 2015) - hereafter referred to as the CDM Regulations - attach a legal obligation to designers. Using a hazard perception test (Hayne et al., 2015), this work investigated if a lack of site experience has an impact on designers' ability to identify construction hazards within designs and hence hinders them in achieving designs with, as far as reasonably practicable, minimal hazards.
Through the presentation of additional results and further analysis, this report builds on the paper by the same authors presented at the 2015 conference of Conseil International du Bâtiment W099 (Hayne et al., 2015).

\section{Background}

The foundation of modern building engineering is a combination of craft knowledge, rules of thumb and the application of science (Blockley, 1980). Early builders were proficient in the mathematics and science of their time and the crafts associated with building. The Roman Marcus Vitruvius stated that '... [a]rchitects who have aimed at acquiring manual skill without scholarship have never been able to reach a position of authority to correspond to their pains, while those who relied only upon theories and scholarship were obviously hunting the shadow, not the substance. But those with a thorough knowledge of both, like men armed at all points, have the sooner attained their object and carried authority with them' (Gelernter, 1995: p. 66).

It is acknowledged that accident causation is often complex and multi-faceted (Gambatese et al., 2008; Gibb et al., 2006; Martínez Aires et al., 2010). However, research has been undertaken in the UK that shows a potential link between design and construction accidents while accepting that design is often not the sole cause and other factors also contribute to accidents (Haslam et al., 2005).

The results of research by Haslam et al. (2005) align with European Union directive $92 / 57 / \mathrm{EEC}$, which states that '... unsatisfactory architectural and/or organizational options ... at the project preparation stage have played a role in more than half of the occupational accidents occurring on construction sites in the Community' (EC , 1992: 26. 8. 92, p. 6). The research by Haslam 
et al. (2005) suggests that little improvement had been made in the decade following the introduction of the CDM Regulations (HMG, 1994), the UK's response to the EU directive.

The effectiveness of the implementation of the European directive in EU member countries was reviewed by Aires et al. (2010: p. 257), who found that it is difficult to isolate the effects of the directive as '... there have clearly been other factors and initiatives occurring in EU member states over this period - it is not possible to differentiate conclusively between these different influences'. Former Health and Safety Executive (HSE) senior inspector John Anderson suggested that while the legislation has created a huge done little else but deliver training courses, generate paperwork and increase construction costs (Anderson, 2003).

Considering such comments, it is reasonable to assume that many UK designers fail to appreciate the benefits of design for safety (DfS). Researchers have said that many designers do not recognise the impact on safety that they, as designers, can make (Haslam et al., 2005). Several barriers for designers have been suggested, including lack of resources and time, cost, client requirements and a lack of tacit knowledge (Behm, 2005; Haslam et al., 2005).

Trethewy and Atkinson (2003: p. 187) defined the principle of DfS as '[i]mproved safety, health and environment outcomes through better design...' In order for this process to be effective, hazards need to be identified during the design process and, where possible, eliminated or minimised (Behm, 2005; Toole and Gambatese, 2008; Trethewy and Atkinson, 2003).

An issue that designers must overcome is that design information generally represents the completed artefact and does not include information pertaining to the construction techniques and processes needed to realise the project (Hadikusumo and Rowlinson, 2002, 2004). Scheer (2014) took this further by purporting that modern three-dimensional (3D) digital models become simulations of the actual artefact and are not a representation that drawings have been for a millennium. Designers are reliant on tacit knowledge that has been gained through experience (Gangolells et al., 2010; Hadikusumo and Rowlinson, 2004; Morrow et al., 2015). It is suggested that this knowledge could be acquired during periods of work on construction sites (Hayne et al., 2014). In the UK, design engineers were originally required to spend time based on-site, but this is no longer the case as both ICE and the IStructE accept an aggregation of short site visits provided that key objectives are met (ICE, 2015; IStructE, 2014) - an approach often criticised by engineers who have spent time on-site and appreciate the unique training opportunity that it provides. Hayne et al. (2015: p. 163) interviewed several experienced engineers who articulated forthright views on the subject: 'People are now cobbling together through site meetings enough days to qualify', 'Well, it's a cop out really isn't it' and '... attending site meetings and doing an inspection and a walk round site just doesn't do it'. awareness of health and safety (H\&S) within the industry, it has

Prior to the 1980s, engineers typically followed one of two routes to become chartered: the first by gaining an accredited degree at a university or polytechnic followed by training within a work environment or, alternatively, by attending night classes and day release programmes at colleges while working. The latter route allowed people to rise through the profession, becoming draughtsmen, designers or chartered engineers, often bringing practical craft knowledge into the office.

It is interesting that while researchers have highlighted a potential link between design and construction hazards (Haslam et al., 2005) and identified barriers to achieving safer designs, including the lack of tacit knowledge (Behm, 2005; Haslam et al., 2005), there is a dearth of research exploring site experience and the ability to identify and mitigate hazards in designs. Anecdotal evidence suggests that tacit knowledge of construction processes and their associated hazards could be gained from periods of site experience (Hayne et al., 2015). This would also align with the previous training requirements of ICE and IStructE where designers were required to have periods of full-time site experience. This research aims to fill this research gap by exploring the relationship between site experience and the ability to identify and mitigate hazards in designs.

\section{Test method}

A hazard perception test was developed using a purpose-made design with numerous design, construction, spatial and maintenance hazards incorporated (Hayne et al., 2015). The aim of the test was to determine if students and design practitioners are able to identify H\&S hazards in designs and to establish if site experience impacts hazard identification. Four types of hazard were identified to be included within the test, as set out in Table 1 .

It was decided that a design specifically created for the test would be utilised for the following reasons.

- A significant number of hazards could be incorporated.

- All types of hazards could be incorporated.

Table 1. Description of types of hazards used in the test

\begin{tabular}{|c|c|}
\hline Type of hazard & Example of hazard \\
\hline Spatial hazard & $\begin{array}{l}\text { Roof access hatch adjacent to roof edge } \\
\text { Trip hazards at door threshold until } \\
\text { computer floor is installed }\end{array}$ \\
\hline $\begin{array}{l}\text { Construction } \\
\text { process hazard }\end{array}$ & $\begin{array}{l}\text { Concrete drilling for service holes } \\
\text { Constructing masonry walls in deep } \\
\text { excavations }\end{array}$ \\
\hline Design hazard & $\begin{array}{l}\text { Lack of explanation of complex stability } \\
\text { system } \\
\text { Two bolt-baseplate connections for steel } \\
\text { columns }\end{array}$ \\
\hline $\begin{array}{l}\text { Maintenance and } \\
\text { operation } \\
\text { hazard }\end{array}$ & $\begin{array}{l}\text { - Safe access to plant room } \\
\text { Roof access hatch adjacent to roof edge }\end{array}$ \\
\hline
\end{tabular}


Management, Procurement and Law

Volume 170 Issue MP2
Design hazard identification and the link

to site experience

Hayne, Kumar and Hare
- A wide range of construction materials and forms of construction could be included.

- The number of drawings required to convey the design intent could be managed.

A design of a four-storey concrete-framed office block with a steel rooftop plant room was produced. The design included over 60 examples of hazards, although it is inevitable that other hazards will exist of which the test creator is unaware.

The design was developed as the equivalent of being part way through stage 4 of the Royal Institute of British Architects' plan of work, 'technical design'. A design at this stage should still be subject to a final review within a design office and would, therefore, provide a realistic activity for the test participants.

A series of two-dimensional (2D) elevations, plans, sections and details, along with 3D images, were produced. An example is shown in Figure 1.

Before any tests were undertaken, the test method and examples of the drawings were shown to several academics experienced in research on the built environment as well as experienced engineers. This was considered appropriate to validate the test and ensure that the test was realistic and challenging and would generate meaningful results. A pilot test was also conducted on a small number of construction students at a different institution to confirm that the instructions and procedures for the tests were practical. The results of the pilot test were not used in the analysis of data as the students had a general construction background and not a specialised civil engineering education.

The first test was undertaken by final-year civil engineering students at a university selected for the following reasons.

- It has one of the largest cohorts of civil engineering students in the UK.

- It is highly ranked in the Complete University Guide and The Sunday Times league tables for civil engineering.

- Students undertake a year's industrial placement in their penultimate year.

The second test was conducted on structural engineers working for a firm of consulting engineers selected for the following reasons.

- The company has a high profile in the industry.

- The company undertakes in-house training for safety by design.

- The company has a large graduate intake each year.

All participants completed a background questionnaire requesting information pertaining to the following: details of education; duration of site experience - full-time or day visits; the type of construction site; and details of the specific work undertaken. This information enabled an assessment to be made of their experiences that would permit meaningful analysis of the test results.
Of the 47 students who took part in the test, 39 had undertaken a year's industrial placement, with 25 being site-based, eight being office-based and six having a combination of both. The site experience gained by the students in their industrial placement ranged from setting out to supervising and inspections on a wide range of construction projects. Six of the students had a combination of both site- and office-based experience, and two were categorised as not having applicable site experience as they had been based in the site office undertaking tasks such as updating drawings, designing formwork and undertaking structural analysis, which were not considered relevant site experience. The overall requirement of site experience to be considered applicable was that the test participants had to have been based on-site and undertaking activities that brought them into daily contact with construction processes and workers.

For the students with both site- and office-based experience, it was impossible to assess if their ability to identify and mitigate hazards was a result of their site- or office-based experience. However, the test is designed to assess if designers with site experience can identify and mitigate hazards more effectively; therefore, these students were classed as having site experience. It is also acknowledged that the practising engineers with site experience also have design experience.

The experience of the six practitioners with full-time site experience ranged from acting as the client resident engineer to working as a labourer and joiner on-site before returning to university.

The test participants were provided with the 2D drawings and requested to give details of as many hazardous processes, operations or forms of construction as possible and how they could be mitigated.

\section{Test results}

\subsection{Results of hazard perception test undertaken by students}

In total, 47 students took part in the test, with 25 students having undertaken periods of relevant site experience during their industrial placement. The students identified 510 hazards; the details are shown in Table 2.

Although the participants had been requested to identify hazards that were specific to the design, a number also identified hazards that were generic in nature - for example, the general danger of concrete burns. It is acknowledged that an understanding of generic $\mathrm{H} \& \mathrm{~S}$ issues is important but, in this context, it does not exhibit an ability to identify hazards within designs. Accordingly, the results were filtered to remove generic hazards, leaving 462 specific hazards for further analysis.

The specific hazards were categorised as a construction process hazard (constructing brick facade), a spatial hazard (no stair access to plant room) or a design hazard (lack of bracing in plant room). The resulting distribution was split to identify if the students had site experience; see Figure 2. 
Management, Procurement and Law Volume 170 Issue MP2
Design hazard identification and the link

to site experience

Hayne, Kumar and Hare
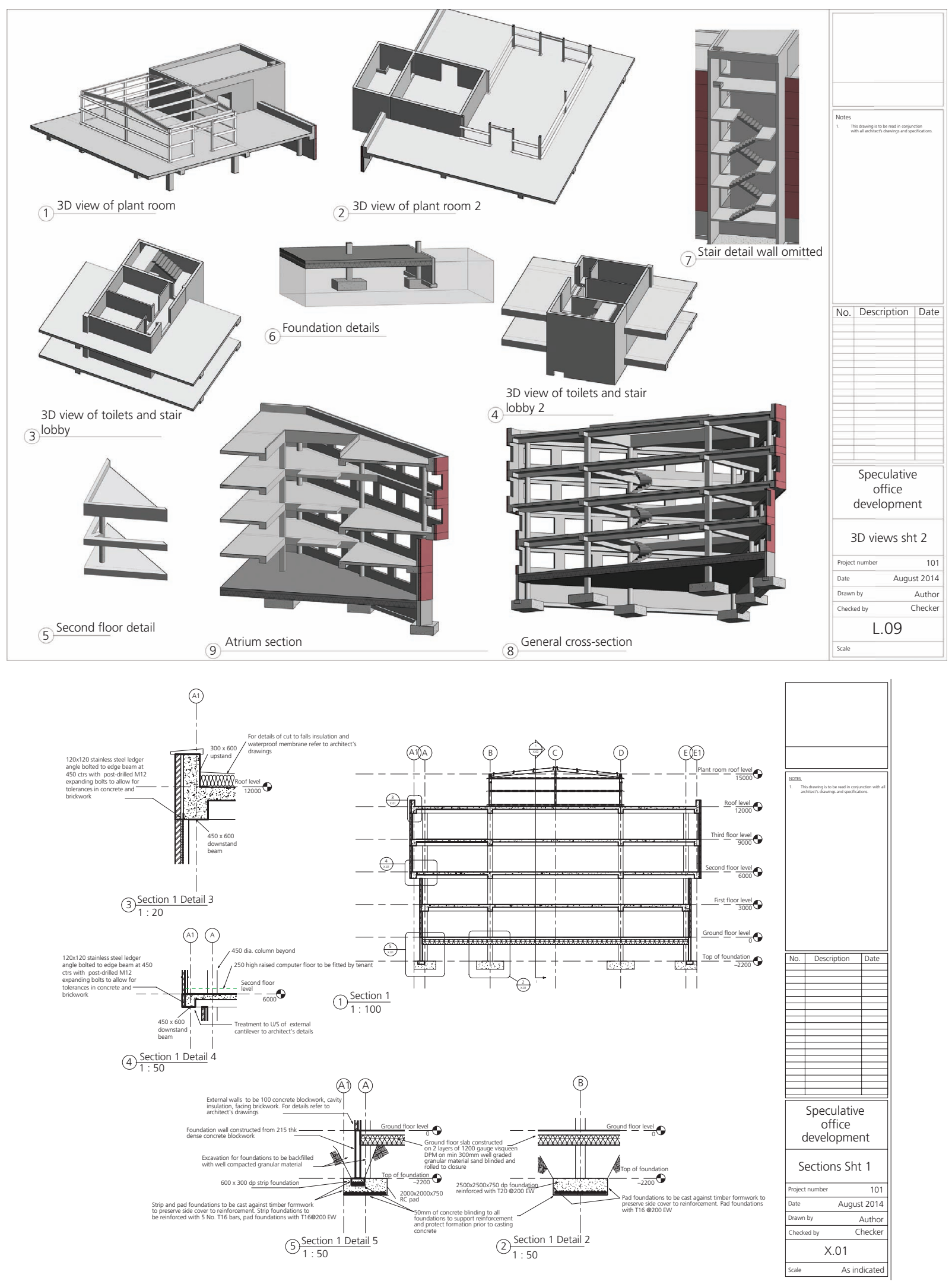

Figure 1. Examples of the layout of $2 \mathrm{D}$ and $3 \mathrm{D}$ drawings used in the hazard tests 
Design hazard identification and the link

to site experience

Hayne, Kumar and Hare

Table 2. Number of hazards identified by students

Total number of hazards identified

Maximum number of hazards identified by a student

Minimum number of hazards identified by a student

Average number of hazards identified by a student

The distribution of the process hazards indicates a visible difference of 36 between the students who had site experience and those without, although the difference was not statistically significant, possibly due to the sample size.

It was observed that the quality of the description of the hazard and the associated mitigation varied in detail and quality, with some well-reasoned responses such as

ne lifting problems associated with dense concrete blockwork and the suggestion to change to lightweight blocks

v the hazards associated with the requirement to core concrete for services and the suggestion to coordinate the design and make allowance for services in the base structural design.

There were also other much more ambiguous responses that relied on the use of personal protective equipment (PPE) to manage the hazard, examples of which were

a cement burns when constructing brick facade and the need to wear gloves

a the danger of kneeling on tying wire and the requirement to wear knee pads and safety glasses.

An independent and industry-recognised scoring mechanism was developed to categorise the quality of the specific responses in order that further analysis of the data could be undertaken. The HSE's Leadership and Worker Involvement Toolkit Number 3, Management of Risk When Planning Work: the Right
Priorities (HSE, 2011), was used, as the document sets out the hierarchy of management of hazards from the highest level, elimination of the hazard, to the lowest level, the provision of PPE (see Table 3).

Using these criteria, 389 hazards and proposed mitigations were classified, with 73 being unclassified. The main reasons for the hazards being unclassified were that no proposals of how to mitigate the hazard were included, the hazards were a duplication by the same student or the student had misread/misunderstood the drawings. The results are shown for the students with and without site experience in Figure 3.

Hazards are classified as category 1, the highest level, when a hazard has been identified within the design and the associated mitigation has eliminated the hazard(s). For instance, identifying that the brickwork facade required prolonged periods of work at height for the bricklayers and the potential of building material falling from working platforms; when this is combined with a suggestion to use prefabricated facade panels the particular hazards are eliminated. Correspondingly, hazards classified as category 5 are the worst solution as a hazard has been identified but the only mitigation is to use PPE.

The largest difference between the number of hazards identified by students with or without site experience was found to be with the category 1 hazards. Accordingly, a chi-square goodness-of-fit test was carried out between the two groups: $\chi^{2}(1, N=117)=$ $4 \cdot 15, p=0 \cdot 042$, indicating that the difference was statistically significant and had not occurred by chance. The results for the remaining categories indicated that site experience had no bearing on the results.

\subsection{Practitioner test results}

The practitioner sample population was composed of 12 participants, the entire staff of an office of consulting engineers,

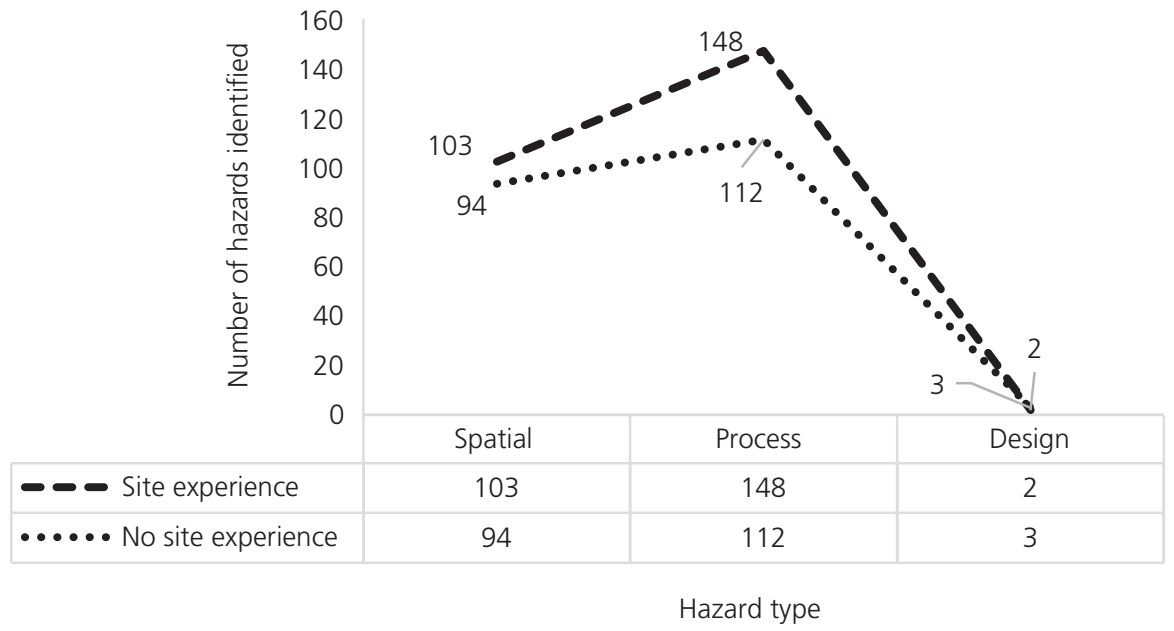

Figure 2. Types of hazards identified by students and extent of site experience 
Table 3. Categories of hazard control according to Management of Risk When Planning Work (HSE, 2011)

\begin{tabular}{|c|c|}
\hline 1: Elimination & $\begin{array}{l}\text { Redesign the job or substitute a substance so that the hazard is removed or eliminated. For example, duty holders } \\
\text { must avoid working at height where they can }\end{array}$ \\
\hline 2: Substitution & $\begin{array}{l}\text { Replace the material or process with a less hazardous one. For example, use a small mobile elevating work platform to } \\
\text { access work at height instead of a stepladder. Care should be taken to ensure that the alternative is safer than the original }\end{array}$ \\
\hline $\begin{array}{l}\text { 3: Engineering } \\
\text { controls }\end{array}$ & $\begin{array}{l}\text { Use work equipment or other measures to prevent falls when working at height cannot be avoided. Install or use } \\
\text { additional machinery such as local exhaust ventilation to control risks from dust or fumes. Separate the hazard from } \\
\text { operators by methods such as enclosing or guarding dangerous items of machinery/equipment. Give priorities to } \\
\text { measures that protect collectively over individual measures }\end{array}$ \\
\hline $\begin{array}{l}\text { 4: Administrative } \\
\text { controls }\end{array}$ & $\begin{array}{l}\text { These are all about identifying and implementing the procedures needed to work safely - for example, reducing the } \\
\text { time workers are exposed to hazards (e.g. by job rotation), prohibiting use of mobile phones in hazardous areas, } \\
\text { increasing safety signage and performing risk assessments }\end{array}$ \\
\hline $\begin{array}{l}\text { 5: Personal protective } \\
\text { clothes and controls }\end{array}$ & $\begin{array}{l}\text { Only after all the previous measures have been tried and found ineffective in controlling risks to a reasonably practical level } \\
\text { must PPE be used. For example, where the risk of a fall cannot be eliminated, use work equipment or other measures to } \\
\text { minimise the distance and consequence of a fall (should one occur). If chosen, PPE should be selected and fitted by the } \\
\text { person who uses it. Workers must be trained in the function and limitation of each item of PPE }\end{array}$ \\
\hline
\end{tabular}

except for two directors who were outside the UK at the time. The experience, education, role and extent of full-time site experience of the sample are outlined in Table 4.

The practitioners identified 154 hazards, with the breakdown of the hazards identified shown in Table 5.

Sixteen generic hazards were excluded, leaving 138 specific hazards, which were categorised as construction process hazard, spatial hazard or design hazard, with the results of the analysis shown in Figure 4.

Again, but to a lesser extent than with the students, the description of the hazard and the associated mitigation varied in detail and quality. The practitioner responses were, therefore, again categorised according to Management of Risk When Planning Work: the Right Priorities (HSE, 2011). Using this system, 108 hazards were categorised, with exclusions being for similar reasons as used on the students' tests, which allows direct comparison between the results of the student and the practitioner tests (see Figure 5).

A chi-square goodness-of-fit test was undertaken for the distribution of category 1 hazards between the engineers with site experience and those without. The results, $\chi^{2}(1, N=35)=8 \cdot 26$, $p=0 \cdot 0068$, indicate that the difference was statistically significant if the practitioners had site experience.

Noting the distribution of spatial, process and design hazards identified by the students and practitioners illustrated in Figures 2

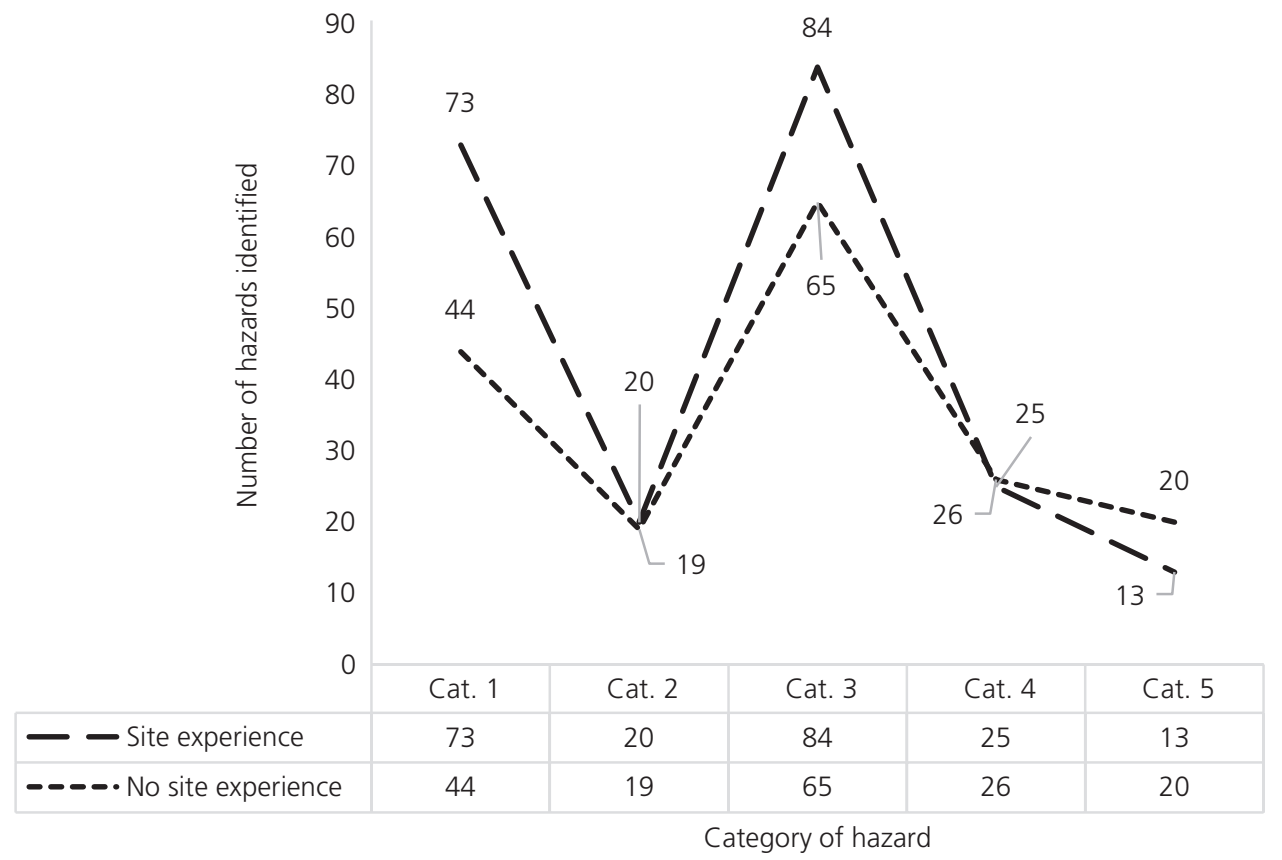

Figure 3. Hazards identified by students distributed by category and site experience 
Table 4. Roles and experience of practitioners

\begin{tabular}{lcclc} 
& Years in industry & Education & \multicolumn{1}{c}{ Professional role } & Has full-time site experience? \\
Engineer 1 & 10 & MEng & Senior structural engineer & No \\
Engineer 2 & 13 & MEng & Associate director & Yes \\
Engineer 3 & 1 & BSC & Structural engineer & No \\
Engineer 4 & 8 & MEng & Senior structural engineer & Yes \\
Engineer 5 & 0 & MEng & Graduate structural engineer & No \\
Engineer 6 & 1 & BSC, MSC & Graduate structural engineer & Yes \\
Engineer 7 & c. 20 & BSC & Technical director, structures & Yes \\
Engineer 8 & 9 & BSc, MSC & Senior structural engineer & Yes \\
Engineer 9 & 19 & MEng, MSt & Project director & Yes \\
Engineer 10 & 18 & HND & Associate technician & No \\
Engineer 11 & 15 & Hssociate technician & No \\
Engineer 12 & 8 & HND & Structural technician & No
\end{tabular}

MEng, Master of Engineering; BSc, Bachelor of Science; MSc, Master of Science; MSt, Master of Studies; HND, Higher National Diploma

Table 5. Number of hazards identified by practitioners

$\begin{array}{lr}\text { Total number of hazards identified } & 154 \\ \text { Maximum number of hazards identified by a practitioner } & 24 \\ \text { Minimum number of hazards identified by a practitioner } & 3 \\ \text { Average number of hazards identified by a practitioner } & 12.8\end{array}$

and 4 , a $t$-test for independent samples was also carried out on the numbers of design hazards identified and mitigated by the practitioners and students. The results were as follows: practitioners, $N=12, M=2 \cdot 42, S_{\mathrm{D}}=3 \cdot 26$; students, $N=47$, $M=0 \cdot 11, S_{\mathrm{D}}=0 \cdot 31, t(57)=4 \cdot 91, p<0 \cdot 001$.

\section{Discussion of results}

\subsection{Spatial, process and design hazards}

Separating hazards into spatial, process and design hazards produced some potentially interesting relationships. For the students, $1 \%$ of the hazards that they identified were design hazards, whereas for the practitioners, $21 \%$ of the hazards that they identified were design related. As indicated by the $t$-test, the results were statistically significant and the variance may be caused by the practitioners' greater experience of design issues. This hypothesis is strengthened by considering the number of design hazards identified by those practitioners with site experience and those without, 17 and $4 \%$, respectively. The practitioners with no site experience were generally less experienced and included the three technicians, two graduate engineers and a senior engineer with 10 years of industry experience. The antithesis is that the practitioners with site experience are generally more experienced, having a total of 59 years of industry experience.

The students' experience of the construction industry is understandably limited. However, they all have experience of the

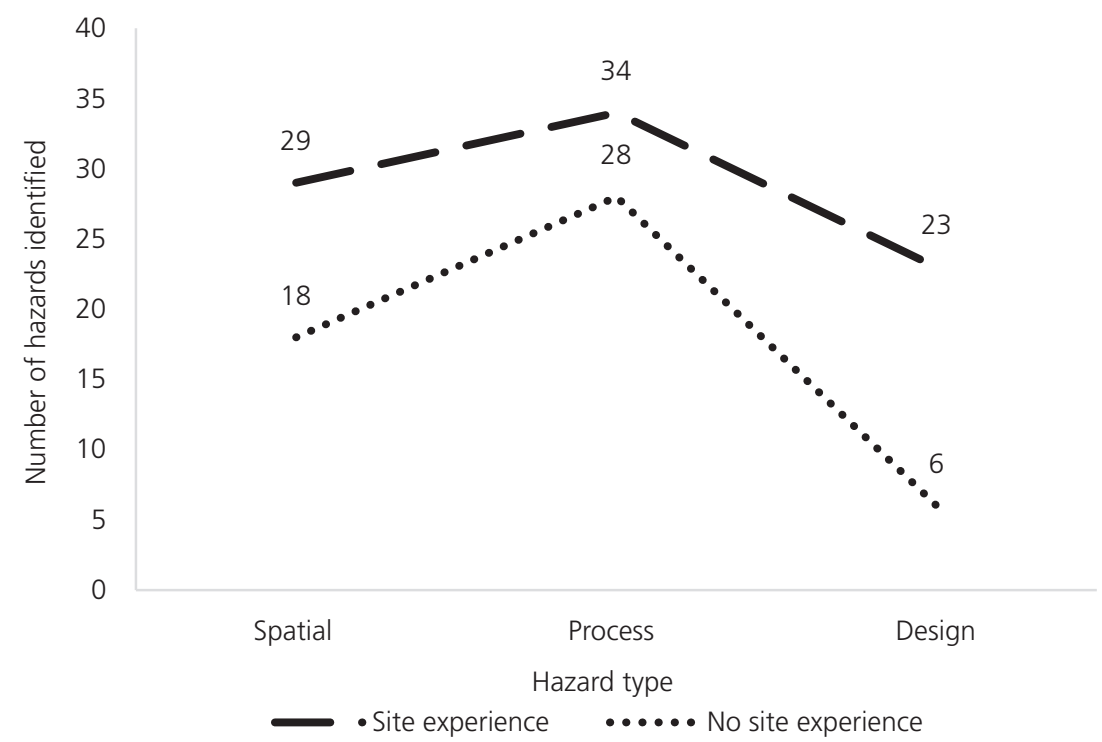

Figure 4. Types of hazards identified by practitioners and extent of site experience 


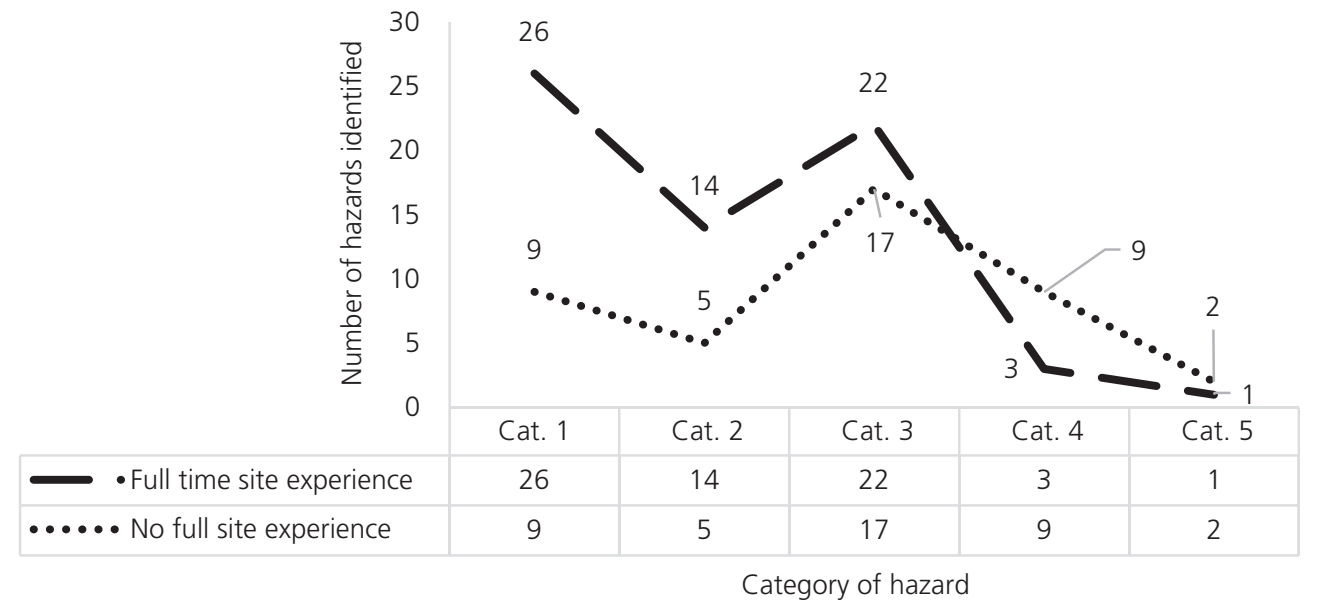

Figure 5. Hazards identified by practitioners distributed by category and site experience

built environment, living in houses/apartments, attending schools/ universities and visiting shops and so on, which form part of the wider built environment. Considering this aspect, it is, therefore, not surprising that $42 \%$ of the hazards they identified fell into the spatial category, compared with $34 \%$ identified by the practitioners. Most of these hazards rely on an understanding of how buildings operate or are maintained rather than how they are constructed. Credence is given to this posit as the split between the spatial hazards identified by students with and without site experience was only $2 \%$.

\subsection{Hazards categorised by Management of Risk When Planning Work}

Categorising the identified hazards and associated mitigation measures according to the HSE document Management of Risk When Planning Work: the Right Priorities (HSE, 2011) provides the highest level of analysis through the link with recognised industry practices of managing hazards during the entire life cycle of a project: design, construction, operation/maintenance and demolition.

The distribution of hazards across the five categories is noticeably different between the students and practitioners (Figures 3 and 5) with regard to the proportion of category 5 hazards identified. While the practitioners identified three category 5 hazards $(3 \%$ of the hazards they identified), the students identified 33 (8.5\%). Once more, the numbers are quite small, and care should be taken not to infer trends that cannot be supported. That said, there is a different distribution of category 5 hazards, and it is likely that this is due to the students' lack of experience. This lack of experience could be hindering some of the students' ability to mitigate hazards once they have been identified. Instead of mitigating the hazard, the students suggested that PPE should be worn by the operators. For the category 5 hazards identified by the students, the ratio of those having site experience to those without is $2: 3$. The increased number identified by the students without site experience could also give some credence to the issue of experience, although the results are not statistically significant.

When the highest classification of category 1 hazards are reviewed, the students and practitioners with full-time site experience identified and eliminated more hazards than the participants without site experience, $26 / 9$ and $73 / 44$ for the practitioners and students, respectively. Chi-square goodness-of-fit tests indicate that the results were statistically significant: $\chi^{2}(1, N=117)=4 \cdot 15, p=0 \cdot 042$ and $\chi^{2}(1, N=35)=8 \cdot 26$, $p=0 \cdot 0068$. The figures are interesting as they indicate a potential link between full-time site experience and the ability to identify and mitigate hazards in designs.

The experiences of the students were generally consistent with each other in that they were of similar age, attended schools and had undertaken similar curricula at university. The significant difference in their experience is their industrial placement years. The industrial year provided the students with a diverse and differing array of experiences, either site-based or office-based. This is noteworthy when considering the identification of the category 1 hazards as this difference appears to have impacted their ability to identify and eliminate hazards.

In contrast, and as expected, the spread of experiences of the practitioners was potentially much more diverse. Although they entered the industry with experiences aligned with the students, once in work they will have been exposed to varying and disparate situations. During their careers, they will have worked on a range of diverse projects with differing design teams, clients and contractors. The differences in ranges of experiences gained by the students and practitioners are analogous to travelling the wrong way through a funnel (Figure 6). While at university, students are within the spout of the funnel and are generally constrained. Once they graduate and start work, they pass into the main body of the funnel and acquire a wide and diverse spread of experiences. 


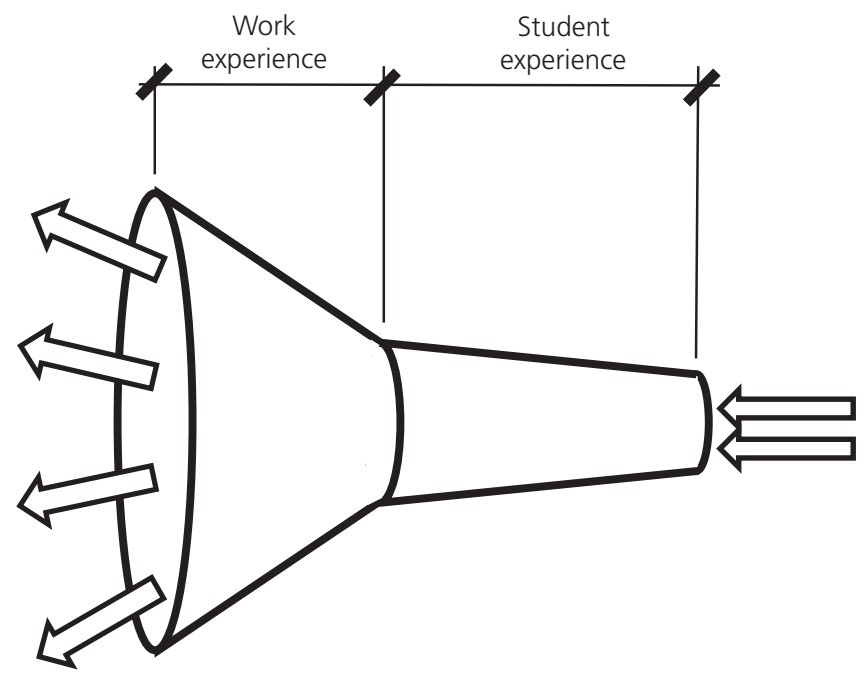

Figure 6. Experiences of students and practitioners

Considering the practitioners, it should be noted that the engineers with full-time site experience had generally also spent more time in the industry. The facility to acquire a much broader spread of experiences within the work environment also raises the potential that numerous other factors could be increasing their ability to identify and mitigate hazards.

The combination of student and practitioner findings supports the hypothesis that having prolonged periods of site experience enhances the ability to identify and mitigate hazards within designs. This could be linked to the research of Haslam et al. (2005) and Behm (2005), who identified that a barrier to effective hazard identification and mitigation was lack of tacit knowledge. If such tacit knowledge is being gained during periods of site experience, this work builds on the previous research in addition to providing experiential evidence to support previous anecdotal evidence of the importance of site experience in the training and development of engineers.

\section{Conclusions and recommendations}

The findings of this research indicate a substantive link between extended periods of site experience and the ability to identify construction process hazards in design, a phenomenon that is evident for both students and practising engineers/designers.

- Students and practitioners with site experience could identify and mitigate significantly more category 1 hazards than those with no site experience.

- No difference was evident in being able to identify spatial hazards, as the entire sample had a similar experience of living in the built environment.

- The practitioners identified and eliminated significantly more design hazards corresponding to their increased experience of design.
While the results are not surprising, and many in the industry have argued this point for some time, empirical evidence is now available that supports previous anecdotal evidence. This link has been identified at a time when the main UK institutions are accepting an aggregation of short site visits as an alternative to the extended periods of site experience previously required to achieve chartered status within ICE and the IStructE. Additionally, with the increased academic background required to progress within the industry, it is argued that the practical knowledge formerly brought into design offices by staff progressing through the day release and night school routes is also being lost.

The UK construction industry is now experiencing its third evolution of the CDM Regulations, and it is questionable if the design engineers of today are suitably equipped to identify and mitigate hazards in their designs.

It is acknowledged that the test results are from single tests on students and practitioners and further tests are required to confirm or refute the hypothesis discussed earlier.

\section{Practical relevance and potential applications}

The link identified between site experience and the ability to identify construction hazards within designs has significant practical relevance at a time when graduates are no longer required to have periods of training based on construction sites. Accepting that it can be difficult to gain appropriate site exposure, it is suggested that the industry needs to evaluate the effectiveness of graduate training programmes to ensure that suitable experience is being gained. If this does not happen, there is a danger that the principles of eliminating design hazards that are enshrined in the CDM Regulations will be unachievable.

The rapid uptake of digital technologies, in particular building information modelling, arguably offers opportunities to develop solutions that could utilise the parametric attributes of the technologies. It is suggested that further research be undertaken to develop educational tools linked to the technology.

In the meantime, the use of the hazard test utilised in this research is being developed and adopted as a training and development tool for graduate design engineers and practitioners in the industry.

\section{REFERENCES}

Aires MD, Rubio Gámez MC and Gibb A (2010) Prevention through design: the effect of European directives on construction workplace accidents. Safety Science 48(2): 248-258.

Anderson J (2003) Construction safety in 2003 - time for radical action. Proceedings of the Institution of Civil Engineers - Municipal Engineer 156(3): 175-178, http://dx.doi.org/10.1680/muen.2003.156.3.175. ASCE (American Society of Civil Engineers) (2016) Engineers Guide to Pre-licensure Experience. ASCE, Reston, VA, USA. See http://www. asce.org/uploadedFiles/Education_and_Careers/Licensure/Content Pieces/Engineers\%20Guide-flierFINAL.pdf (accessed 01/12/2016). 
Design hazard identification and the link

to site experience

Hayne, Kumar and Hare
Behm M (2005) Linking construction fatalities to the design for construction safety concept. Safety Science 43(8): 589-611.

Blockley D (1980) The Nature of Structural Design and Safety. Ellis Horwood, Chichester, UK.

Crossrail (2016) Healthy by Design: a Guide for Crossrail Design Teams. Crossrail, London, UK. See http://www.cbhscheme.com/Documents/ Healthy by Design Version 3 (accessed 02/01/2016).

EC (European Community) (1992) Council Directive 92/57/EEC of 24 June 1992 on the implementation of minimum safety and health requirements at temporary or mobile constructions sites (eighth individual Directive within the meaning of Article 16 (1) of Directive 89/391/EEC). Official Journal of the European Communities L245. See http://eur-lex.europa.eu/legal-content/EN/TXT/PDF/? uri=CELEX:01992L0057-20070627\&from=EN (accessed 08/11/2015).

Gambatese JA, Behm M and Rajendran S (2008) Design's role in construction accident causality and prevention: perspective from an expert panel. Safety Science 46(4): 675-691.

Gangolells M, Casals M, Forcada N, Roca X and Fuertes A (2010) Mitigating construction safety risks using prevention through design. Journal of Safety Research 41(2): 107-122, http://dx.doi.org/10.1016/ j.jsr.2009.10.007.

Gelernter M (1995) Sources of Architectural Form: a Critical History of Western Design Theory. Manchester University Press, Manchester, UK.

Gibb A, Haslam R, Gyi D, Hide S and Duff R (2006) What causes accidents? Proceedings of the Institution of Civil Engineers - Civil Engineering 159(6): 46-50, http://dx.doi.org/10.1680/cien.2006.159.6.46.

Hadikusumo BHW and Rowlinson S (2002) Integration of virtually real construction model and design-for-safety-process database. Automation in Construction 11(5): 501-509.

Hadikusumo BHW and Rowlinson S (2004) Capturing safety knowledge using design-for-safety-process tool. Journal of Construction Engineering and Management 130(2): 281-289.

Haslam RA, Hide SA, Gibb AGF et al. (2005) Contributing factors in construction accidents. Applied Ergonomics 36(4): 401-415, http://dx. doi.org/10.1016/j.apergo.2004.12.002.

Hayne G, Kumar B and Hare B (2014) The development of a framework for a design for safety BIM tool. In Computing in Civil and Building Engineering (Issa R and Flood I (eds)). ASCE, Reston, VA, USA, pp. $49-56$.
Hayne G, Kumar B and Hare B (2015) Evaluating the effectiveness of modern building engineering studios to deliver design for safety (DfS). In Proceedings CIB W099 Belfast 2015 (Behm M and McAleenan C (eds)). EEI Publishing, Downpatrick, UK, pp. 160-168.

HMG (Her Majesty's Government) (1994) Health and Safety.

The Construction (Design and Management) Regulations 1994. Her Majesty's Stationery Office, London, UK, Statutory Instrument 1994 No. 3140. See http://www.legislation.gov.uk/uksi/1994/3140/contents/ made (accessed 23/04/ 2013).

HMG (2015) Health and Safety. The Construction (Design and Management) Regulations 2015. Her Majesty’s Stationery Office, London, UK, Statutory Instrument 2015 No. 51.

HSE (Health and Safety Executive) (2011) Management of Risk When Planning Work: the Right Priorities. HSE, Liverpool, UK. See http:// www.hse.gov.uk/construction/lwit/assets/downloads/hierarchy-riskcontrols.pdf (accessed 23/01/2015).

ICE (Institution of Civil Engineers) (2015) Professional Review Guidance. ICE, London, UK. See https://www.ice.org.uk/getattachment/my-ice/ membership-documents/professional-review-guidance/professionalreview-guidance.pdf.aspx (accessed 12/11/2015).

IStructE (Institution of Structural Engineers) (2014) Initial Professional Development. IStructE, London, UK. See http://www.istructe.org/ webtest/files/31/319c117a-a1e4-475e-b5c9-01711684155c.pdf (accessed 30/05/2012).

Martínez Aires MD, Rubio Gámez MC and Gibb A (2010) Prevention through design: the effect of European directives on construction workplace accidents. Safety Science 48(2): 248-258.

Morrow S, Cameron I and Hare B (2015) The effects of framing on the development of the design engineer: framing health and safety in design. Architectural Engineering and Design Management 11(5): 338-359.

Scheer DR (2014) The Death of Drawing: Architecture in the Age of Simulation. Routledge, New York, NY, USA

Toole TM and Gambatese J (2008) The trajectories of prevention through design in construction. Journal of Safety Research 29(2): 225-230.

Trethewy RW and Atkinson M (2003) Enhanced safety, health and environment outcomes through improved design. Journal of Engineering, Design and Technology 1(2): 187-201.

\section{How can you contribute?}

To discuss this paper, please email up to 500 words to the editor at journals@ice.org.uk. Your contribution will be forwarded to the author(s) for a reply and, if considered appropriate by the editorial board, it will be published as discussion in a future issue of the journal.

Proceedings journals rely entirely on contributions from the civil engineering profession (and allied disciplines). Information about how to submit your paper online is available at www.icevirtuallibrary.com/page/authors, where you will also find detailed author guidelines. 